\title{
Game based learning: a case study on designing an educational game for children in developing countries
}

\author{
Susan M. Ferreira \\ LICEF Research Center \\ Télé-Université du Québec \\ Montreal, Canada \\ susan.ferreira@licef.ca
}

\author{
Charles Gouin-Vallerand \\ LICEF Research Center \\ Télé-Université du Québec \\ Montreal, Canada \\ Charles.Gouin-Vallerand@teluq.ca
}

\author{
Richard Hotte \\ LICEF Research Center \\ Télé-Université du Québec \\ Montreal, Canada \\ rhotte@teluq.ca
}

\begin{abstract}
Despite the efforts and global policies to achieve universal primary education, there are still 58 million children, roughly between the ages of 6 and 11, out of school globally. Although previous studies showed the value of serious games for learning, not enough efforts were made to apply serious games to reduce children illiteracy. Understanding the complexity of this problem, we put together a multidisciplinary research team, and an industrial partner, to work on the design of a serious game for children without access to school. In this paper, we present the preliminary results of our case study, showing the main design challenges faced to develop such tool and proposing solution to overcome those issues. We aim to call the attention of the research community about the urgent need of more studies in this field and we argue that our results could be used as starting point for taking forward future work in this direction.
\end{abstract}

Keywords-Serious games; children education; mobile learning; game learning scenario; ICTD

\section{INTRODUCTION}

Despite the efforts and global policies to achieve universal primary education, humanitarian agencies call attention to the fact that there are still 58 million children, roughly between the ages of 6 and 11, out of school globally [1]. Although the increasing penetration of technologies in developing countries could provide more access to education in poor and rural areas, a core concern among ICTD (Information and Communication Technologies and Development) scholars is that there is a disproportionate emphasis into providing physical access to computers and Internet without adequate attention on how these technologies could be used to actually impacts human development [2], [3] \& [4].

With the advance of computer and mobile technologies a vast amount of educational serious games have been designed to contribute for children's education. Previous studies had stated that "in the past 10 years, the field of learning games has grown dramatically" [5, p.1], that "serious Games (SGs) are gaining ever more interest as an instructional tool" [6, p.392] and that "Educational games are being backed up in the Technology-Enhanced Learning domain as strategies that can lead to worthy learning outcomes." [7, p.192]. Unfortunately, most of current efforts in this area aimed to complement the daily school learning or focus only in a particular learning content, not offering strong solutions for providing children's education in lieu of availability of regular schooling.
In this research, we aim to contribute to solving this issue by designing a serious game for tablet devices that will be adapted to the individual self-learning, particularly for children in developing countries. The initial stage of the project focus on children from India. The overall goal is to adapt the contents of math and English subjects, offered from Kindergarten to Grade 12, in a standard Indian Curriculum onto an application embedded within a tablet PC. The application would be applied in both learning scenarios, as a supplement to daily school learning or in lieu of availability of regular schooling, raising the challenge to offer a high level of motivation and user-friendliness for a student to effectively educate him/herself. This challenge is treated regarding three different aspects: motivation and engagement, identifying children's previous knowledge and knowledge transfer. Furthermore, other key design challenges were identified concerning learning and gaming balance, collaborative learning and school curriculum and children's cognitive development.

This is an interdisciplinary project that joins together an industrial partner, that produce low-cost tablet devices to developing countries, and researchers from Game Design, Education, Learning system engineering, Cognitive computing Human-Computer Interaction and ICTD. In this paper, we present our initial design solution, which is based on a collaborative design process that included this interdisciplinary team. Moreover, this design solution is based on an exhaustive literature review in all team's expertise. Thus, in the Section II, we present the main aspects of the literature review in children game based learning, children tablet interaction, game instructions for children and technology-enhanced learning initiatives in developing countries. In the Section III, we present our approach, giving details on the collaborative design process. Following, in Section IV, we present the case study of our initial design to the research community. In this section we discuss the main identified challenges and present strategies that were applied to ensure that our design addresses the elements of the learning Curriculum, the profile of the learners and their capabilities. Finalizing, conclusions and future steps are presented. 


\section{LITERATURE REVIEW}

\section{A. Children Game Based Learning}

Games-based learning and the use of video games in education contexts has been a subject of research for decades. One of the primary uses of computers in education with simulations and games has been for supporting drill and practice for factual recall [8]. Later one, several games were integrated into school's curriculum as enrichment exercises out of the class, e.g.: "Alga-Blaster", "Reader Rabbit", or "Knowledge Munchers" [9]. As in the previous examples, most of serious games for children education aim to complement the daily school learning and not enough effort has been made to create serious games that promote children self-learning.

The value of learning through gaming has been recognized in the children's education field for more than a decade, Simulation, case studies, role playing, and gaming are related teaching methods based on experiential learning. They permit experience or experimentation with a situation modeling the real world [10]. This kind of learning could be particularly well suited for young learners [11]. Game-based learning is seen as an option to address the learning and motivation requirement of the existing generation of students [12] and evidences indicate that games implementing pedagogical design can strengthen and support children's cognitive abilities [13].

Historically, the concept of "serious game" was created by Clark Abt [14]. He defined serious games as games that have an explicit and carefully thought-out educational purpose, and are not intended to be played primarily for amusement. The references here were primarily to the use of board and card games. More recently, [15] defines serious game as "a mental contest, played with a computer in accordance with specific rules that uses entertainment to further government or corporate training, education, health, public policy, and strategic communication objectives."

Although many serious games have been developed, the current major challenge lies in translating interest and potential into actual adoption and use [6]. Researches highlight the challenge to balance between fun and educational measures as a key challenge in serious game design [16], [6]. Klopfer et al. suggests that designing teams should focus on both learning and game play simultaneously from the beginning of the design process [16]. Furthermore, Arnab et al. call attention to the fact that "despite the digital games' potential in terms of interactivity, immersion and engagement, more work is still required to understand how to better design, administrate and evaluate digital games across different learning contexts and targets" [6, p.392].

\section{B. Children Cognitive Development and Tablet Interaction}

Previous research has demonstrated that children from different ages vary in their cognitive and motor skills and consequently in their strategies to interact with mobile devices. According to Piaget's theory [17], [18] children's cognitive development can be described in the following stages:
- Sensorimotor stage (from birth to 2 years): Privileges motor activity. Acquisition of knowledge is achieved through physical interactions and trial-and-error mechanisms.

- Preoperational (2-7 years): Children learn language skills, develop their motor skills and develop their memory and imagination.

- Concrete operational (7-11 years): Intellectual development, children make use of logical reasoning and systematically manipulate symbols that are connected to concrete objects and events.

- Formal operational (adolescence through adulthood): Extends children's reasoning toward abstract and hypothetical concepts.

Previous researches on children computer interaction have shown that children are not as proficient as adults when interacting with tablet devices [19]. In fact, in the preoperational stage children are still developing their cognitive and motor skills and previous research have shown that younger children presented more difficulties to interact with tangible devices than children with a more advanced stage of cognitive development [19], [20], [21]. Numerous children-tablet interactions issues, that can be connected to children continuously development of motor skills, have been previously detected, for instance: difficulties with drag and drop interaction in touch devices [22], [23], [21], difficulties with multi-touch [21], [24], not recognized gestures [20] or misinterpreting touch actions [24], [20]. Other researchers identified aspects related to young children's cognitive development that should be taken into consideration when design tablet application for them, such as holding only one thing at memory at time [25] or manifesting centralization, focusing their attention in only one characteristic at time [21]. These studies did not include children from developing countries and a common outcome from their research is that children's interaction with tablet applications varies intensely from pre-school to high-school age.

\section{Multimodal Interaction and Game Instructions}

Adding to touch interaction, which is very popular for tablet applications, previous educational tools and games for children also explored multimodal interaction techniques. Children's gestures have been applied to learn to write letters [20], children peephole navigation using movement-based and touch-base applications have been explored [23], as well the use of stylus pen [21] and the use of the tablet's camera or tangible objects [26]. Although previous works had explored different interaction strategies with children, our literature review indicates that there is still much to be understood regarding children multimodal tablet interactions for serious games, yet more contributions in this field are needed.

Different strategies for game instruction were identified by previous researches, compiling positive and negative aspects of each of them. Providing text instructions is commonly applied in digital games, but is not recommended for children in pre-school age [27]. Researchers suggest using audio, graphics and animation to substitute writing communication, 
to choose words that are appropriated to users reading levels and to use large font size [25]. On the other hand, animation demonstrations and audio guidance were considered largely appropriate for preschoolers. Figures 1 and 2 show examples of animation instructions. In the Figure 1 an animated hand demonstrates the action the children should perform in the game. In the Figure 2, an animated character (squirrel) shows the player the correct answer.

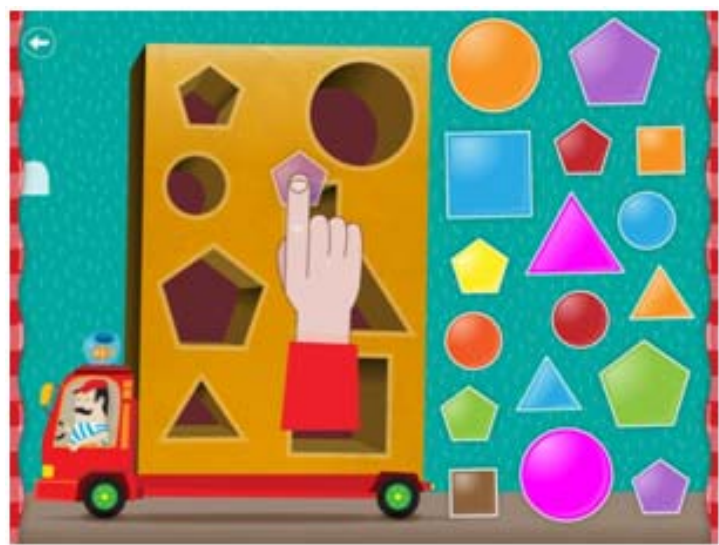

Figure 1-Animated hand game instruction [28].

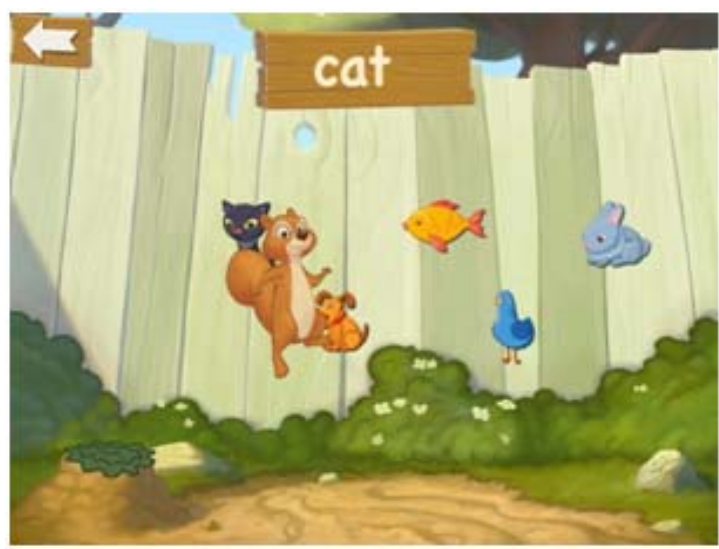

Figure 2-Animated character game instruction [29].

In relation to visual state change, results show that it was effective in calling attention to interactive items, but not as a teaching tool (demonstrating how users should touch items) [27]. These previous studies indicate that in a serious game that focus on children from a vast age range, the best strategy is to combine different types of instructions, initially combining audio with animations and visual state changes and, as children's literacy improves, start including also text instructions.

\section{Technology-Enhanced Learning in Developing Countries}

Aiming to reduce the words illiteracy previous researches had explored the use of digital educational tools to promote learning in developing countries. In 2008, the Pocket School project reviewed possible opportunities with mobile learning technology to counter the effects of the education inequality in Latin America [30]. Their results suggest that "mobile learning technology, thanks to its portability, low production costs, versatile features, and significant memory space, has the potential to provide indigenous children with learning materials that could possibly teach them to read".

Also aiming to provide children's literacy, literacy tablets were designed to initiate and scaffold literacy learning toward self-sufficiency [31]. The tablets were given to children in rural villages in Africa that had no schools, and the children had no access to literacy. The tablet was designed to help remotely located rural children teach themselves to read. The results showed that the children, which took part in the study, encountered technology and literacy for the first time by using the tablet. Their results called attention to the highly collaborative aspect of children's tablet interaction in those communities and that children become passionate learners and also teachers of their community [32].

Another recent research describes a collaborative development of a digital, multi-language reading tool that facilitates translation of local stories by Kenyan community groups, led by a librarian, into a mother tongue [33]. The aim of the application is to break the chain of illiteracy, allowing parents with lowest levels of literacy explore stories with their children. An interesting result is that besides supporting the official language was also important to provide a multilanguage system that supports the different local mother languages.

A common outcome of these initiatives is that they demonstrated the value of applying mobile applications to teach children without access to schools. Moreover, each of them embrace a specific learning content, not providing a continuous education tool to be applied in the lack of regular schooling.

\section{APPROACH}

Understanding that designing a serious game for children without access to school includes important aspects from different fields, a multidisciplinary research team worked in the design process. Our team was composed by 14 researchers and an industrial partner, which produces and commercializes low cost tablets for developing countries. The research team is composed by professionals from Game Design, Education, Learning system engineering, cognitive computing, HumanComputer Interaction and ICTD.

The first step of the design process was conducting literature review in the different specialties. In this stage, researchers meet periodically to discuss the outcomes of each field.

After understanding the key aspects from the literature review, a collaborative brainstorming workshop was conducted. In this workshop 13 members of the research team were divided in 4 groups, each group discussed one key aspect of the game. During the activity participants had to move from one group to other, mixing group passing (passing the ideas/topics from a small group to another one) and stepladder techniques (adding new participants gradually to a group to reduce the Groupthink effect).

Finally, the outcomes of the brainstorming section were analyzed and refined by a small group, which developed the 
first serious game low fidelity prototype. These initial ideas were applied in a three round design process including prototype design, workshops on prototype evaluation and discussion, and design refinement. In total three low-fidelity prototypes were developed and discussed among the team.

\section{Case Study: A Serious Game for Children Without ACCESS TO SCHOOL}

As a result from the literature review and the collaborative multidisciplinary design process we identified key challenges for developing serious games for children without access to schooling. Next we present details on our main objective, a discussion on the key initial design challenges and present strategies we applied to overcome these issues.

\section{A. Objective and Target Audience}

The main objective of the presented serious game is to provide a learning tool for children from 6 to 17 years old that have no or limited access to education resources. Therefore, such serious game must take into account a series of parameters about the profile of the learners, the technology background of the children, their culture, their level of education, etc. Moreover, such game must manage at some point their motivation, which is normally managed by the teachers in physical schools.

Thus, an interdisciplinary research team was built to address the challenges of building such serious game. Therefore, the research team had to combine different disciplines' contributions in order to create a learning system for mobile devices that will be adapted to the individual selflearning, particularly for children in developing countries. Inside of this main goal we identified three sub goals:

- Identifying the best pedagogical practices and the best learning scenarios by using games and electronic tablets.

- Define how to develop a digital learning environment based on an efficient scenario allowing students to control their learning in the way that they can identify what he learns and how he learns it.

- Design of children-tablet interactions to support the learning scenarios.

Our target audience is children from 6 to 17 years old without access to regular schooling. For the first stage of the project, the target audience is children from India and we focus on the Indian's school Curriculum related to learning math and English. In the second stage of the project, we aim to expand our target adapting the tool for children from other developing countries.

\section{B. Key Design Challenges and Proposed Solutions}

As an outcome of the literature review and collaborative design process, we identified, and proposed solutions, to key challenges to design a serious game for children out of schooling. The main challenge identified in this study is the lack of teacher, and possibly also a lack of literate family member, to guide the learners through their education process.
This issue is treated in this study regarding three different aspects: motivation and engagement, identifying children's previous knowledge and knowledge transfer. Adding to it, other key design challenges were identified regarding learning and gaming balance, collaborative learning and curriculum and children's cognitive development. We discuss next, details on each challenge and our proposed solutions.

\section{1) Maintain Learner's Motivation and Engagement}

Since our target audience is children without access to school one of the main challenges for our serious game was to maintain children engagement with the application and their motivation to self-learning. From the literature review we understood the high potential of serious gaming for learning [6] and value of RPG (Role Playing Games) to offer a motivating context that elicits engagement into language learning [34].

Based in our literature review and collaborative design process, in this study we propose applying a RPG game mechanics as a strategy to motivate and engage students into self-learning English and Mathematics. Aiming to do so, we combined RPG quest base structure [35] with the Quest based learning methodology [36] into the designing of an educational serious game. Each level of the game corresponds to one year of the school Curriculum and the learning scenarios are presented as quests (i.e. tasks that the player must complete in order to gain a reward) in an RPG game. More details on this quest learning structure can be observed in Section C.3 (Guest structure).

\section{2) Identify Children Previous Knowledge}

As mentioned previously, the aim of our learning tool is to take into account children from different ages. From our literature review we identified a high inequality level in educational opportunities in India [37], with children leaving the school in different ages. In order to bring those children back to education is crucial to allow players to start playing the game from different levels, ranging from preschoolers to more advanced high-school years.

One challenge into this direction is to identify the correct educational level for each student, as each of them may have different formal and informal previous learning experiences. The solution we suggest for this issue is to design a selfassessment activity, objectifying to identify players' previous knowledge, skills and age. This activity should be composed by short puzzles, presented to children when they start playing the game for the first time. The outcomes of the activity should then be applied as input to personalize and propose the appropriate game level, and learning competences, for each child.

\section{3) Knowledge Transfer}

In our literature review we found different perspectives regarding whether children learn differently when information is presented in a fantastic context vs. a realistic context. Previous researchers pointed out the fact that young children may have difficulties to transfer solutions from the fantasy world into the real worlds [38], [39]. Other recent study evaluated the performance of pre-school children into learning 
new words in real word and fantasy contexts. Their results suggest that stories focusing on fantastical elements encourage greater learning [40].

Taking both perspectives into account, our design solution incorporated fantasy aspects (e.g. history line and game objects) with strategies that support learning transfer. Adapting to each learning scenario, we defined special quests containing activities to promote debriefing and knowledge transfer. Those activities are incorporated in bridge quests connecting different learning scenarios, they may include a debriefing activity, a video showing a similar learning content in a real word context or an activity where the learner needs to apply his knowledge to build a project (virtually or uploading a picture from a creation in the real world). More details on these strategies are presented in Section C.3 (Guest structure).

\section{4) Learning and Gaming Balance}

Related work showed that a key challenge in serious game design is to find the correct balance among learning and gaming [6], [16]. Perhaps due the multidisciplinarity of the research team, strategies focusing on learning and gaming came up from the initial stages of our study and during all the design process (literature review, collaborative brainstorming section and prototype discussions).

Following recommendations from previous research [16] we focused in both aspects, learning and gaming, from the beginning of the design process. The result of this strategy was to design learning gaming scenarios and game mechanics that include both gaming and learning aspects. An example of this strategy is the development of two key game objects, one focusing in the learning aspects of the tool (student portfolio) and the other focusing on gaming (artifact repository). In Section C.4 (Main game objects), details regarding both objects are presented.

\section{5) Collaborative Learning}

Collaborative learning has been studied in the education field for decades (e.g. [41], [42]). In gaming, the value of massive multiplayer online role-playing games (MMORPGs), to foster social interaction and to facilitate collaborative learning, have also been discussed (e.g. [43], [44]). Furthermore, a recent ICTD research, on technology-enhanced learning, showed a highly collaborative aspect of children's tablet interaction in developing countries [32].

These previous work impulse us to propose a serious game strategy that support online collaboration and collaborative learning. This strategy faced two limitations, first regarding how to guaranty children's safety online without an adult supervision [25] and second, regarding developing countries communication network infrastructure. In distant rural villages in developing countries we cannot rely on strong data connections, for that reason, our tool needs to operate with $2 \mathrm{G}$ communication networks and low rate of data transfer. Taking those issues in consideration, we developed an initial multiplayer strategy, by including a game-ranking showing the best players inside of each community. As a next step we aim to explore other strategies of collaboration, as sharing an object in the game [45] or applying Bluetooth wireless technology.

\section{6) School Curriculum and Children Cognitive} Development

Since our target audience varies from 6 to 17 years old, our design strategy must take into consideration children from different ages. As presented in the literature review section, children's cognitive development and consequently tablet interaction varies intensely in this age range. Furthermore, the learning content and competences presented in the game should be adapted to the different ages and school curriculum.

Our strategy for this challenge is to create a game architecture that can be adapted to different ages and learning content. We defined 12 game levels, each of them corresponding to one year of regular schooling. In the first stage of the project, each game level will focus on math and English content, corresponding to Indian's school Curriculum. As the player moves forward in the game, the application will increase its complexity in relation to the learning content (according to the school curriculum), game mechanics, game instructions, aesthetics and user interaction.

\section{Game Elements Summary}

We present next a summary of the main game elements and game design strategies. Following the conclusion and future work perspectives are presented.

\section{1) History Line Summary}

"The Wise Wizard lost his fight against the evil Troll, his legendary enemy. While the Wizard, defeated and injured, is recovering in the forest, the Troll sneaks into his house and steals his prized possessions, a collection of magical artifacts. The set of magical artifacts were dispersed within the fantasy realm, hidden as everyday objects. Without his magical artifacts, the Wizard has little power and cannot protect the world against the Troll. As a consequence of the Troll's actions, natural disasters started to happen everywhere.

The Wise wizard is still weak and cannot solve the problem alone. He searches for a group of young people that will become apprentices to assist him to find his magical artifacts and bring his magic back. These apprentices will have to travel through the world, solve puzzles and win games to find the magical artifacts, bringing the magic and well-being back to the world."

\section{2) The Physical World Overview}

The game world is composed by several islands. These islands are organized in three levels, respecting children cognitive load. Each island represents a different environment, giving learners autonomy to navigate through the world and perform learning activities in different settings. As shown in Figure 3, each island contains and open-air environment and may contain one or more smaller closed subspaces (e.g.: house, market, cave). 


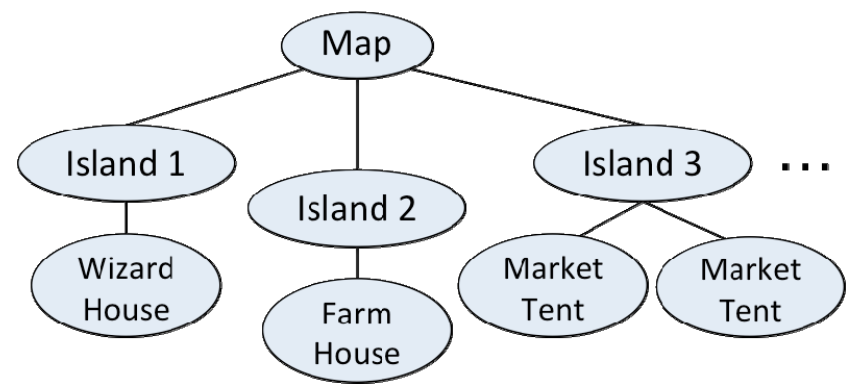

Figure 3-Physical world islands overview.

\section{3) Guest Structure}

When playing the game learners will be presented with several quests in each level. Figure 4 shows a Linear Hub Pattern [35] for our quest representation.

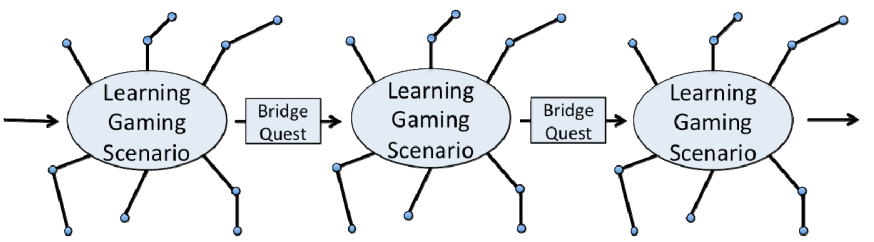

Figure 4-Series of learning gaming scenarios, each of them with one or more activities.

Quests can serve a learning purpose (teaching players school curriculum contents) or push forward the narrative. As Figure 4 illustrates, each learning gaming scenario is composed by a set of basic quests (1 to N). Each scenario corresponds to a specific learning competence and the different scenarios are connected by bridge quests. Next we present details on this quest structure:

Arrowhead Questing: For each learning scenario player will be presented with a number of quests. The quest starts with a simple objective and eventually narrow down to specific objectives of great significance.

Contextualizing Quests: These quests are primarily based on creating a believable and compelling game space. They help the player ease into the world while also introducing them to core mechanics of the game. These quests are mainly applied in the game introduction and later when new mechanics of the game are introduced.

Basic Quest: Basic learning activities, learners receive "points" when completed.

Bridge Quest: It connects different learning scenarios. It could have three different structures according to the learning scenario and game narrative:

- Building activity: Build something putting together what the player learned in the previous quests.

- Finding artifacts: Player will find a magical artifact that will give him/her spells that may be used to solve future quests.

- Debriefing: players do a debriefing activity to reflect in what they learned.
Unlock Quest: This quest allows players to move to the next level (school grade) of the game. After completing this quest player finds a new magic creature and the next game level is unlocked.

\section{4) Main Game Objects}

Magic book: It is the learning portfolio, where he can amass skills and personal projects. Besides other game functionalities this object is used as a learning diary showing details on children's learning activities. It saves children projects and show details regarding the learning activities performed.

Magic tent: It is the learners' space, a magical tent that the student carry and can bring up any time. Inside the tent there is a big room containing their game artifacts and magical creatures. This will be the "safe" zone for the learner, where they can view their game collected items.

\section{5) Main Game Characters}

Apprentice: Playing Character. Travel around the world solving puzzles to find the lost artifacts. As they solve the enigmas and collect the artifacts, he/she gains wisdom and magical spells to pass game levels and win the Troll.

Smart Wizard: Non-playing character. It is the player's mentor and tutor. Gives player advice, useful tips and propose activities. Help the learner if they have difficulties during the game.

\section{CONCLUSIONS AND FUtURE WORK}

This study calls attention to the value of technology enhancing learning and serious games into contributing in enriching lives of citizens in developing countries. More specifically, this study aims to call the attention of the research community for the lack of studies and the opportunity to apply serious games to contribute in reducing the children and adult illiteracy in developing countries.

Our preliminary results, from the literature review and multidisciplinary design process, identified key challenges for developing serious games for children without access to schooling. Based in three rounds of low-fidelity prototype design and discussions, we propose design solutions aiming to address these challenges. We argue that this initial understanding of the problem could be used as starting point for future work in this field.

We are currently planning the next step of this study, which refers to conducting user studies with children. In the first stage we aim to evaluate the design ideas using a lowfidelity prototype and discussing with children aspects that could be improved in the tool. These outcomes will be applied as input for developing a high-fidelity prototype, which will be applied in the second round of evaluation.

\section{Acknowledgment}

We thank all team members of the KSMS project for their collaboration and valuable contributions to this study. We specially acknowledge to Eric Le Magoariec, Isabelle 
Aubuchon and Kelsey Schmitz. We also thank DataWind for their collaboration and support. This project is founded by a MITACS Accelerate Cluster research grant.

\section{References}

[1] UNESCO Institute for Statistics (UIS) and UNICEF, "Fixing the broken promise of education for all: Findings from the Global initiative on Out-of-School Children," Montreal, 2015.

[2] M. Warschauer, Technology and Social Inclusion: Rethinking the Digital Divide. The MIT Press; New Ed edition, 2004.

[3] A. Johri and J. Pal, "Capable and convivial design (CCD): a framework for designing information and communication technologies for human development," Inf. Technol. Dev., vol. 18, no. 1, pp. 61-75, Jan. 2012.

[4] S. M. Ferreira, S. Sayago, and J. Blat, "Going Beyond Telecenters to Foster the Digital Inclusion of Older People in Brazil: Lessons Learned from a Rapid Ethnographical Study," Inf. Technol. Dev., vol. (in press), p. 21, 2016.

[5] J. Groff, J. Clark-Midura, V. E. Owen, L. Rosenheck, and M. Beall, "Better learning in games: A balanced design lens for a new generation of learning games," 2015.

[6] S. Arnab, T. Lim, M. B. Carvalho, F. Bellotti, S. de Freitas, S. Louchart, N. Suttie, R. Berta, and A. De Gloria, "Mapping learning and game mechanics for serious games analysis," Br. J. Educ. Technol., vol. 46, no. 2, pp. 391-411, Mar. 2015.

[7] J. Melero and D. Hernández-Leo, "A Model for the Design of Puzzle-based Games Including Virtual and Physical Objects," J. Educ. Technol. Soc., 2014.

[8] D. H. Jonassen, "Integrating learning strategies into courseware to facilitate deeper processing," in Instructional designs for microcomputer courseware, Hillsdale, New Jersey: Erlbaum, 1988, pp. 151-181.

[9] K. Squire, "Video Games in Education," Int. J. Intell. Games Simul., vol. 2, no. 1, pp. 198-202, 2003.

[10] P. M. Senge, The Fifth Discipline: The Art and Practice of the Learning Organization. Doubleday/Currency, 1990.

[11] A. Szczesna, M. Tomaszek, and A. Wieteska, "The Methodology of Designing Serious Games for Children and Adolescents Focused on Psychological Goals," in Information Technologies in Biomedicine, vol. 7339, E. Piętka and J. Kawa, Eds. Berlin, Heidelberg: Springer Berlin Heidelberg, 2012, pp. 245-255.

[12] M. Prensky, Digital Game-based Learning. McGrawHill, 2001.

[13] R. M. Bottino, L. Ferlino, M. Ott, and M. Tavella, "Developing strategic and reasoning abilities with computer games at primary school level," Comput. Educ., vol. 49, no. 4, pp. 1272-1286, Dec. 2007.
[14] C. C. Abt, Serious games: The art and science of games that simulate life. The Viking Press, 1970.

[15] M. Zyda, "From visual simulation to virtual reality to games," Computer (Long. Beach. Calif)., vol. 38, no. 9, pp. 25-32, Sep. 2005.

[16] E. Klopfer, S. Osterweil, and K. Salen, "Moving Learning Games Forward," Cambridge, MA, 2009.

[17] Piaget and Jean, The Psychology Of Intelligence. Taylor \& Francis, 1999.

[18] A. De Ribaupierre, "Piaget's theory of child development," in International Encyclopedia of the Social and Behavioral Sciences., Oxford, 2001, pp. 11434-11437.

[19] L. Anthony, Q. Brown, J. Nias, B. Tate, and S. Mohan, "Interaction and recognition challenges in interpreting children's touch and gesture input on mobile devices," in Proceedings of the 2012 ACM international conference on Interactive tabletops and surfaces-ITS'12, 2012, p. 225.

[20] L. Anthony, Q. Brown, J. Nias, and B. Tate, "Examining the need for visual feedback during gesture interaction on mobile touchscreen devices for kids," in Proceedings of the 12th International Conference on Interaction Design and Children-IDC '13, 2013, pp. 157-164.

[21] R.-D. Vatavu, G. Cramariuc, and D. M. Schipor, "Touch interaction for children aged 3 to 6 years: Experimental findings and relationship to motor skills," Int. J. Hum. Comput. Stud., vol. 74, pp. 54-76, Feb. 2015.

[22] L. Humphries and S. McDonald, "Emotion faces: the design and evaluation of a game for preschool children," in Proceedings of the 2011 annual conference extended abstracts on Human factors in computing systems-CHI EA '11, 2011, p. 1453.

[23] B. McNally, M. L. Guha, L. Norooz, E. Rhodes, and L. Findlater, "Incorporating peephole interactions into children's second language learning activities on mobile devices," in Proceedings of the 2014 conference on Interaction design and children-IDC '14, 2014, pp. 115-124.

[24] L. McKnight and D. Fitton, "Touch-screen Technology for Children: Giving the Right Instructions and Getting the Right Responses," in Proceedings of the 9th International Conference on Interaction Design and Children-IDC '10, 2010, p. 238.

[25] A. Bruckman and A. Bandlow, "Human-computer interaction for kids," in The human-computer interaction handbook, L. Erlbaum Associates Inc., 2002, pp. 428-440.

[26] Imaginarium, "Imaginarium iwow," 2015. [Online]. Available: http://www.imaginarium.es/iwow-679.htm. [Accessed: 23-Mar-2016].

[27] A. Hiniker, K. Sobel, S. R. Hong, H. Suh, I. Irish, D. Kim, and J. A. Kientz, "Touchscreen prompts for preschoolers: designing developmentally appropriate 
techniques for teaching young children to perform gestures," in Proceedings of the 14th International Conference on Interaction Design and Children-IDC '15, 2015, pp. 109-118.

[28] TinyHands, "TinyHands Sorting 3," 2015. [Online]. Available: https://itunes.apple.com/us/app/tinyhandssorting-3-educational/id639384857? $\mathrm{mt}=8$. [Accessed: 22-Mar-2016].

[29] Bussu, "Bussu Kids," 2015. [Online]. Available: https://www.busuu.com/mobile/kids. [Accessed: 22Mar-2016].

[30] P. Kim, T. Miranda, and C. Olaciregui, "Pocket School: Exploring mobile technology as a sustainable literacy education option for underserved indigenous children in Latin America," Int. J. Educ. Dev., vol. 28, no. 4, pp. 435-445, Jul. 2008.

[31] A. Chang, D. Nunez, T. Roberts, D. Sengeh, and C. Breazeal, "Pre-pilot findings on developing a literacy tablet," in Proceedings of the 12th International Conference on Interaction Design and Children-IDC '13, 2013, pp. 471-474.

[32] A. Chang, L. Tilahun, and C. Breazeal, "Visualisations of Data from the Literacy Tablet Reading Project in Rural Ethiopia," in Proceedings of the EVA London 2014 on Electronic Visualisation and the Arts, 2014, pp. 142-149.

[33] A. Schwartz, E. Kaplan, E. W. Lajoie, T. Terrell, and E. Ajambo, "Using a principal agent model to explain user-centered design challenges for mother tongue reading in Kenya," in Proceedings of the Seventh International Conference on Information and Communication Technologies and DevelopmentICTD '15, 2015, pp. 1-8.

[34] M. Peterson, "Massively multiplayer online roleplaying games as arenas for second language learning," Comput. Assist. Lang. Learn., vol. 23, no. 5, pp. 429-439, Dec. 2010.

[35] G. Smith, "RPG Design Patterns," 2009. [Online]. Available: https://rpgpatterns.soe.ucsc.edu/doku.php?id=start. [Accessed: 22-Mar-2016].

[36] C. C. Haskell, Design Variables of Attraction in Quest-based Learning. Boise State University, 2012.

[37] M. N. Asadullah and G. Yalonetzky, "Inequality of Educational Opportunity in India: Changes Over Time and Across States," World Dev., vol. 40, no. 6, pp. 1151-1163, Jun. 2012.

[38] R. A. Richert, A. B. Shawber, R. E. Hoffman, and M. Taylor, "Learning From Fantasy and Real Characters in Preschool and Kindergarten," J. Cogn. Dev., vol. 10, no. 1-2, pp. 41-66, Apr. 2009.

[39] R. A. Richert and E. I. Smith, "Preschoolers' quarantining of fantasy stories.," Child Dev., vol. 82, no. 4, pp. 1106-19, Jan. 2009.

[40] D. S. Weisberg, H. Ilgaz, K. Hirsh-Pasek, R. Golinkoff, A. Nicolopoulou, and D. K. Dickinson, "Shovels and swords: How realistic and fantastic themes affect children's word learning," Cogn. Dev., vol. 35, pp. 1-14, Jul. 2015.

[41] M. Warschauer, "Computer-Mediated Collaborative Learning: Theory and Practice," Mod. Lang. J., vol. 81, no. 4, pp. 470-481, Dec. 1997.

[42] K. A. Bruffee, "Collaborative Learning: Higher Education, Interdependence, and the Authority of Knowledge. Second Edition.," Nov. 1998.

[43] M. D. Childress and R. Braswell, "Using Massively Multiplayer Online Role-Playing Games for Online Learning," Distance Educ., vol. 27, no. 2, pp. 187196, Aug. 2006.

[44] H. Cole and M. D. Griffiths, "Social interactions in massively multiplayer online role-playing gamers.," Cyberpsychol. Behav., vol. 10, no. 4, pp. 575-83, Aug. 2007.

[45] A. N. Antle, "Exploring how children use their hands to think: an embodied interactional analysis," Behav. Inf. Technol., vol. 32, no. 9, pp. 938-954, Sep. 2013. 